\section{Manicômio em circuito: os percursos dos jovens e a internação psiquiátrica}

\author{
The psychiatric hospital circuit: the trajectories of \\ yong people prior to psychiatric hospitalization
}

\footnotetext{
1 Programa de Pós-graduação em Psicologia Social e Institucional, Universidade Federal do Rio Grande do Sul, Porto Alegre, Brasil.

2 Instituto de Psicologia

Universidade Federal do Rio Grande do Sul, Porto Alegre, Brasil.

Correspondência

A. C. C. Scisleski

Programa de Pós-graduação em Psicologia Social e Institucional, Universidade Federal do Rio Grande do Sul. Rua Ramiro Barcelos 2600 sala 201d, Porto Alegre, RS 90035-003, Brasil. ascisleski@yahoo.com.br
}

\section{Abstract}

This article analyzes psychiatric hospitalization of young patients from a contemporary social-subjective (rather than a psychopathological) perspective, following the trajectory of these youth prior to their admission. The study was conducted at the Center for Comprehensive Psychosocial Care for Children and Adolescents, São Pedro Psychiatric Hospital, in the city of Porto Alegre, Rio Grande do Sul State, Brazil. Recurrent traits in the trajectory of these youth expressed how the health care network functioned with them prior to their hospitalization, with a consistent pattern of socioeconomic deprivation, low schooling, and drug use. Another key aspect was the role of the court system in referring them for hospitalization, adhering to a kind of logic that punished both the youth and the services and paradoxically formed a strategy for access to health services.

Hospitalized Adolescent; Psychiatric Hospitals; Mental Disorders
Andrea Cristina Coelho Scisleski 1

Cleci Maraschin 2

Rosane Neves da Silva 2

\section{Introdução}

Este trabalho parte do tensionamento entre dois campos: o das políticas públicas de saúde mental e o do direito com relação às políticas para a juventude na atualidade.

No Estado do Rio Grande do Sul, Brasil, encontramos algumas concepções antagônicas no contexto das políticas públicas de saúde mental: ao mesmo tempo em que foi o primeiro estado brasileiro a instituir uma lei antimanicomial no âmbito da Reforma Psiquiátrica, foi aqui também que surgiu um movimento de "contra-reforma" caracterizado pela proposição do aumento do número de leitos em hospitais psiquiátricos e pela inauguração de novos hospitais nesta modalidade.

No âmbito nacional, outro exemplo de antagonismo refere-se ao fato de o Estatuto da Criança e do Adolescente - considerado por muitos como uma das leis mais avançadas no contexto mundial - conviver paralelamente com um discurso sobre a redução da maioridade penal.

Este artigo se insere no debate sobre esses tensionamentos contemporâneos, como fruto de pesquisa de Mestrado no seio de uma instituição psiquiátrica hospitalar. Discutiremos os encaminhamentos de jovens para o atendimento no Hospital Psiquiátrico São Pedro (HPSP) e como tais encaminhamentos são reveladores dos modos de operar das instituições que fazem 
parte desta "rede de serviços" que aproximam os campos da saúde mental e do direito.

Consideramos importante propor um outro olhar sobre o assunto, partindo de uma perspectiva social e não de uma nosologia individual. Não estamos, com isso, desconsiderando a importância desse último aspecto, relacionado mais especificamente com o tratamento desses jovens. Nosso interesse consiste em analisar em que medida o que é tomado como individual se refere a uma complexa trama social na qual esses jovens estão inseridos. Questionamos, assim, a unidirecionalidade das idéias e práticas terapêuticas focadas em uma dimensão estritamente individual e que não levam em consideração a trama discursiva que produz a internação desses jovens.

O objetivo deste estudo é mostrar que, embora os percursos dos jovens internados revelem uma trajetória social em comum, ela não é problematizada coletivamente, nem pelos serviços de saúde e tampouco pelos jovens, que não se dão conta das semelhanças entre suas trajetórias.

\section{Mapeando percursos}

O lugar que escolhemos para iniciar o estudo dos percursos é o Centro Integrado de Atenção Psicos- social (CIAPS), unidade do HPSP. O CIAPS/HPSP é formado por uma equipe multiprofissional que atende, prioritariamente, sob regime de internação, a população infanto-juvenil proveniente da 1ạ, 2a e 18a Coordenadorias Regionais de Saúde do Estado do Rio Grande do Sul. As coordenadorias citadas abrangem, respectivamente, os municípios situados na Grande Porto Alegre, no Vale do Taquari e no Litoral Norte.

Cerca de $75 \%$ do público atendido no CIAPS são adolescentes 1 . Esse dado se mantém desde a fundação do CIAPS, em 2001, até hoje. Também é bastante significativo o número de reinternações dos adolescentes no CIAPS, o que correspondeu a $62 \%$ no ano de 2005. Outra informação importante refere-se ao elevado número de encaminhamentos via determinação judicial - $42 \%$ em 2005 - anteriormente, teve um número ainda maior - 66\% em 2002, 54\% em 2003 e 2004 1, conforme a Figura 1.

Também ressaltamos que o maior índice de diagnóstico para a internação de adolescentes no CIAPS/HPSP concerne a "Transtornos Mentais e de Comportamento devido ao Uso de Substâncias Psicoativas" (códigos F10 a F-19 da CID-10 2), chegando a 50\% no ano de 2005. Desde a inauguração do serviço, esse sempre foi o diagnóstico mais incidente sobre os jovens, em ordem crescente, a cada ano. Entretanto, o índi-

Figura 1

Tipos de encaminhamentos ao Centro Integrado de Atenção Psicossocial, Hospital Psiquiátrico São Pedro, Porto Alegre, Rio Grande do Sul, Brasil.

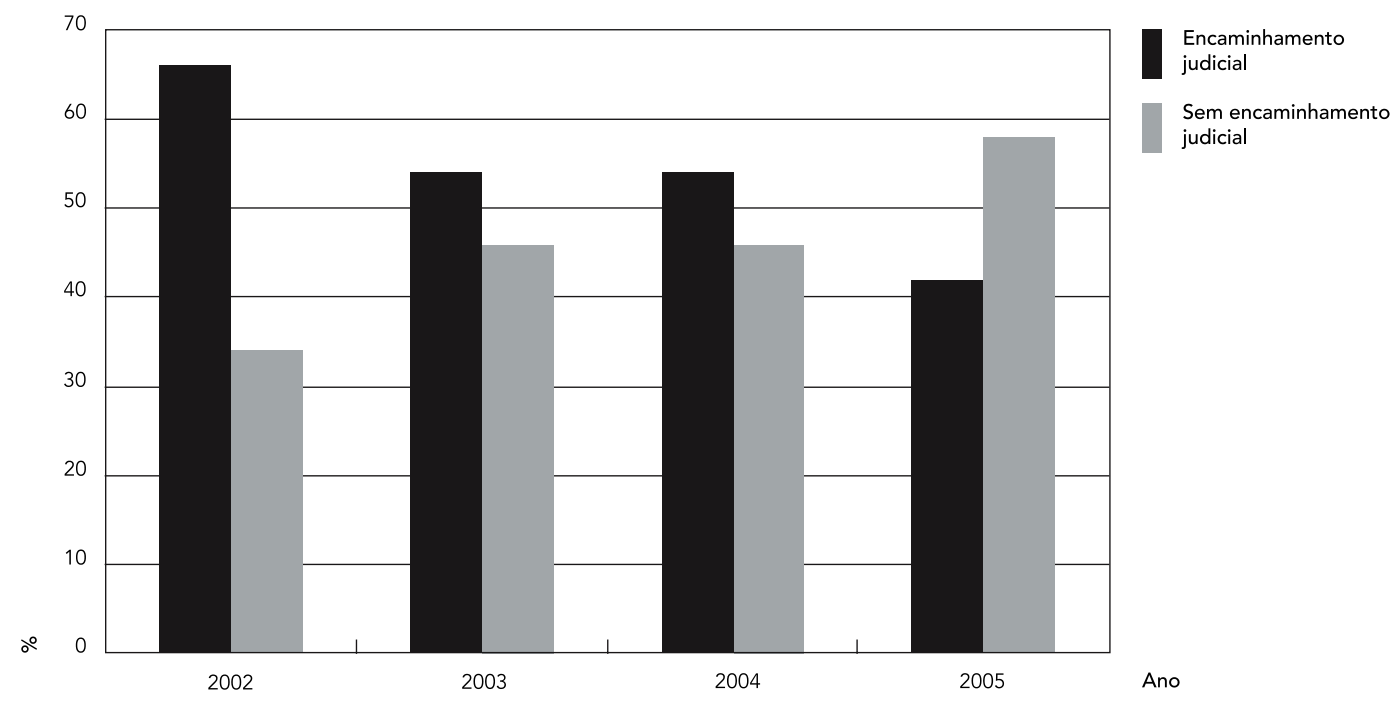


ce de 2005 é o maior entre todos os anos desde o funcionamento do CIAPS/HPSP (Figura 2).

É interessante notar o avanço do diagnóstico F10-F19 no HPSP, uma vez que as instituições psiquiátricas se consolidaram privilegiadamente pelo atendimento de esquizofrênicos e outros casos de psicose, retratando um público diferente do que hoje interna majoritariamente. Podemos, com isso, constatar a mudança ao longo do tempo nas categorias patológicas atendidas. Atualmente, no HPSP a questão da drogadição é a patologia juvenil que mais demanda atendimento, sendo, inclusive, corriqueiramente encaminhada de um modo bastante peculiar: via determinação judicial. Este, na verdade, tem sido o principal motivo de internação de jovens na maioria dos hospitais psiquiátricos 3 .

Esse pequeno registro de características da internação no CIAPS já é suficiente para justificar a ênfase subjetivo-social de nossa proposta de estudo. Em primeiro lugar, chama a atenção que a ordem judicial parece desempenhar um papel dúbio: se, por um lado, é um procedimento que se oferece como uma estratégia de acesso para jovens ao serviço de saúde, por outro, por vezes é utilizado como uma espécie de punição, no sentido de o encaminhamento servir como um recurso auxiliar à disciplinarização dos jovens, ou seja, permitindo um processo de docilização dos mesmos. Podemos também pensar em uma "hierarquia" na rede onde os serviços de saúde se subordinam às demandas judiciais.

\section{Oficinas de percurso: a trajetória dos jovens}

Com o intuito de conhecer os movimentos dos jovens que culminavam com a internação, elaboramos uma estratégia a qual denominamos de oficinas de percurso. Foram realizadas seis oficinas com os adolescentes internados no CIAPS/ HPSP no período de abril a julho de 2005. A Tabela 1 detalha o número de participantes masculinos e femininos em cada oficina. Alguns dos jovens internados não participaram por estarem contidos ou sendo atendidos em consultas clínicas nas enfermarias do HPSP.

Com a intenção de facilitar nossa inserção com os jovens no local, as oficinas ocorreram no

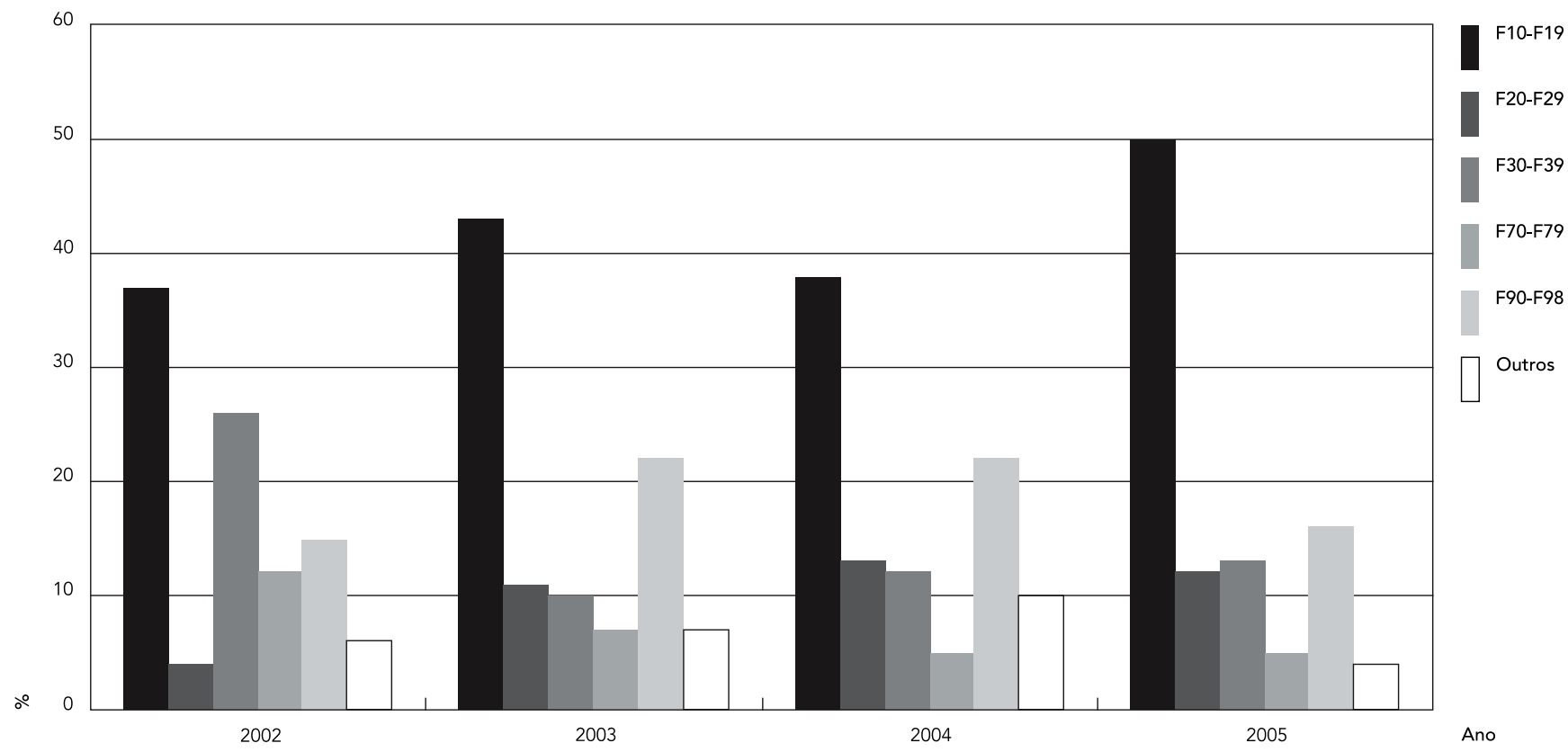

F10-F19: transtornos mentais de comportamento devido a uso de substância psicoativa; F20-F29: esquizofrenia, transtornos esquizotípicos e delirantes; F30F39: transtornos de humor; F70-F79: retardo mental; F90-F98: transtornos emocionais e de comportamento com início ocorrendo na infância e adolescência. 
horário dos grupos terapêuticos - atividade instituída no CIAPS/HPSP, coordenada pela psicóloga responsável. A proposta das oficinas de percurso era a de configurar um modo de interação e de conversação com os jovens em torno da seguinte indagação: "como vocês chegaram até o CIAPS/ HPSP?”. Para isso, disponibilizávamos um material (papel pardo, sucatas e canetas coloridas) e encorajávamos que as respostas à questão fossem representadas de um modo primeiramente visual. No início de cada oficina, esclarecíamos aos jovens sobre os propósitos da investigação e da vinculação do trabalho com a pesquisa acadêmica, solicitando os seus consentimentos e o de seus responsáveis (de acordo com o termo de consentimento livre e esclarecido aprovado pelo Comitê de Ética do hospital). Os jovens elaboravam suas produções e as colocavam sobre o papel pardo. Depois de concluída a tarefa, cada um era estimulado a contar para o grupo o que tinha feito.

Devido à perspectiva de permanência na internação ser de poucas semanas, nossa estratégia era aguardar que todos os que participaram da atividade tivessem tido alta para propormos uma nova edição da oficina. Em média, entre uma oficina e outra, o tempo variou de três a seis semanas.

Além das oficinas, também pesquisamos os prontuários dos jovens e participamos de reuniões nas quais a equipe técnica discutia a situação social e diagnóstica de cada um deles, na intenção de obtermos maiores informações relativas aos percursos recorrentes dos adolescentes que ingressavam no CIAPS.

Quando propusemos a atividade das oficinas como parte de nossa metodologia aos jovens internados, estávamos nos referindo não somente a uma estratégia de abordagem, por exemplo, mas, principalmente, a uma dimensão éticopolítica. Os jovens internados não escrevem em seus prontuários nem registram suas próprias vozes nos espaços formais da instituição.

Dessa maneira, nos posicionamos em prol de uma ética que pretende recuperar a dimensão da experiência e do saber desses jovens 4 , contrária à produção de uma não-existência, de encontro à lógica que gera o epistemicídio 5 - que pode ser entendido pela invisibilização das vivências dos jovens.

\section{Os percursos dos jovens: possibilidades de saída?}

Retomando os dados de nossa pesquisa, cabe destacar ainda uma importante diferença entre os gêneros, pois $61 \%$ dos participantes da oficina
Tabela 1

Quadro geral de jovens internados no Centro Integrado de Atenção Psicossocial, Hospital Psiquiátrico São Pedro, Porto Alegre, Rio Grande do Sul, Brasil.

\begin{tabular}{|c|c|c|c|c|}
\hline & \multicolumn{2}{|c|}{ Participantes das oficinas } & \multicolumn{2}{|c|}{ Não participantes das oficinas } \\
\hline & Masculino & Feminino & Masculino & Feminino \\
\hline G1a & 6 & 2 & 2 & 1 \\
\hline $\mathrm{G} 1 \mathrm{~b}$ & 3 & 4 & - & - \\
\hline G2 & 4 & 3 & 2 & 1 \\
\hline G3 & 4 & 4 & 0 & 0 \\
\hline G4a & 3 & 3 & 1 & 0 \\
\hline $\mathrm{G} 4 \mathrm{~b}$ & 5 & 0 & - & - \\
\hline Total & \multicolumn{2}{|c|}{41} & \multicolumn{2}{|c|}{7} \\
\hline
\end{tabular}

eram adolescentes do sexo masculino, ao passo que $39 \%$ eram do sexo feminino. Além disso, dentro desse contexto, apenas $8 \%$ dos jovens do sexo masculino freqüentavam a escola na ocasião da internação, enquanto $50 \%$ das jovens tinham este vínculo escolar, conforme mostra a Tabela 2.

Ademais, em alguns casos, como veremos adiante, muitos jovens internados no CIAPS/ HPSP já tiveram passagem pela Fundação de Atendimento Sócio-Educativo (FASE-RS) ou, de certa forma, são ameaçados pela possibilidade de irem para lá pelas próprias instituições que os encaminharam ao CIAPS/HPSP. Explicamos que a FASE-RS foi criada para substituir a extinta Fundação Estadual do Bem-Estar do Menor (FEBEM-RS), através de medidas protetivas e de medidas sócio-educativas. No caso de jovens infratores, esta instituição os atende nas modalidades de medidas sócio-econômicas de internação, semi-liberdade ou liberdade assistida.

Para uma discussão sócio-subjetiva dos percursos, selecionamos algumas trajetórias dos jovens, extraídas das oficinas, que abordavam a circulação social que eles traçavam até a chegada ao CIAPS/HPSP. Dentre elas, destacaremos os relatos de Igor, Nelson e Ricardo, apresentados a seguir. Mencionamos que os nomes foram trocados com o intuito de preservar a identidade dos sujeitos.

\section{Curto(s)-circuitos}

Igor, um jovem de 15 anos, morador de um município da Grande Porto Alegre, desenha no papel pardo um campo de futebol e monta com sucatas vários barracos que representam a favela onde mora; em um destes barracos, reproduz os dizeres de um cartaz pendurado na porta de um bar: 
Média de idade e situação escolar dos participantes da oficina de percurso. Centro Integrado de Atenção Psicossocial, Hospital Psiquiátrico São Pedro, Porto Alegre, Rio Grande do Sul, Brasil.

\begin{tabular}{lcccc}
\hline & \multicolumn{2}{c}{ Masculino } & & Feminino \\
& Média de idade & Estuda & Média de idade & Estuda \\
\hline G1a & 14,8 & Não (unânime) & 14,0 & $1 / 2$ \\
G1b & 14,6 & $1 / 3$ & 15,2 & $2 / 4$ \\
G2 & 13,6 & Não (unânime) & 13,3 & $2 / 3$ \\
G3 & 16,0 & Não (unânime) & 15,7 & $2 / 4$ \\
G4a & 15,6 & $1 / 3$ & 15,3 & $1 / 3$ \\
G4b & 16,0 & Não (unânime) & - & - \\
Estudantes (\%) & & 8,0 & & 50,0 \\
\hline
\end{tabular}

"entre se quiser, saia se puder". Ele comenta que o bar é um lugar onde ocorrem muitas brigas que, com freqüência, têm como resultado a morte de alguém. Igor diz que a vida na favela tem muita "correria", explicando que esta "correria" tem a ver com o tráfico de drogas, mas também com a rotina de trabalho daqueles que têm emprego. Conta ainda que foi parar no CIAPS/HPSP - e esta é a sua segunda internação no local pelo mesmo motivo - devido ao consumo de crack e também por participar na venda de drogas.

O jovem diz que no CIAPS não sente "fissura" (vontade de consumir a droga), mas afirma que quando tiver alta e retornar para a favela voltará a usá-la: “Aqui eu não vejo a droga, lá ela vai estar na minha frente o tempo inteiro”. Igor comenta que também ajuda a família com o dinheiro que ganha com o tráfico. Diz que conhece os traficantes da favela, que sabe como o "esquema" funciona, que já está acostumado. Refere que largar as drogas não é uma tarefa possível de ser feita para quem está muito envolvido.

É interessante notar que o próprio jovem fala de si como se já não houvesse mais a perspectiva de um outro modo de vida possível. Se pensarmos nas experiências dos jovens associadas ao trajeto para a internação no CIAPS/HPSP, perceberemos no itinerário de Igor - assim como no de muitos outros internados no CIAPS - que a situação de pobreza sócio-econômica (favela onde mora), o uso de drogas (crack) e a autoria de atos infracionais (furto, tráfico) são aspectos importantes que configuram a internação psiquiátrica; mas, ao que parece, esse jovem se percebe como único protagonista desse percurso. Dessa maneira, tais experiências não são vistas como uma vivência produzida por uma dada configuração social, mas são tomadas pelo jovem no âmbito exclusivo da sua individualidade.
Sobre esse aspecto ressaltamos, conforme aponta Nardi 6, que a produção da subjetividade na sociedade capitalista se relaciona com a supremacia da individualidade. Ou seja, nas palavras do autor 6 (p. 40): "o capitalismo (...) assinala o surgimento de uma sociedade de indivíduos". Com isso, queremos dizer que as subjetividades individualizadas não são um mérito apenas da recorrência dos percursos dos jovens - como ilustra a situação de Igor que atribui a si próprio a dificuldade de sair desse itinerário expresso na própria epígrafe do bar: "entre se quiser, saia se puder" -, mas também refletem a lógica tributária do ideal capitalista contemporâneo que faz do sujeito o único responsável pelo sucesso ou fracasso de sua vida.

Contudo, é relevante também observar que Igor não acredita na ajuda de alguma instituição que possa fazê-lo sair do circuito das drogas. $\mathrm{O}$ jovem, assim, está "adequado" às circunstâncias de seu viver. Ao que parece, a própria medida da internação psiquiátrica não demonstra estar sendo significativa como recurso que pode auxiliá-lo a repensar sua situação no tráfico e, menos ainda, a lhe mostrar alternativas com outras possibilidades de vida.

Como não é a primeira vez que ele está internado no CIAPS/HPSP, percebemos a recorrência de um percurso que já se consolidou: o jovem já baixou anteriormente no CIAPS pelo mesmo motivo que o internou agora, por ordem judicial e com acompanhamento do conselho tutelar; na alta, o plano é que seja encaminhado a uma Fazenda Terapêutica (de cunho religioso) e, como ele não quer ir para esta instituição, é possível que fuja... e, posteriormente, seja reencaminhado ao CIAPS.

Xeque-mate? De um certo modo sim. O próprio Igor fala dessa posição ao dizer que não há 
como encontrar uma saída da via da droga. É o "entre se quiser, saia se puder" que diz respeito, então, não apenas ao funcionamento do bar da favela onde vive esse jovem, mas à situação em jogo no contexto da sua (e não só da sua) internação psiquiátrica.

Outra trajetória importante de ser analisada é a de Nelson, 14 anos, morador de um município próximo à capital gaúcha; está na quarta internação no CIAPS. Na oficina, ele começa desenhando a rodoviária de sua cidade, faz a casa da família onde mora, uma praça e uma maquete da escola que estudava na sua infância (Nelson interrompeu os estudos na quarta série do Ensino Fundamental). Comenta a sua dificuldade em largar as drogas - motivo a que atribui sua baixa no CIAPS - e que se sente abandonado pela família, pois afirma que já está internado há uma semana e não recebeu nenhuma visita dos pais (que não o acompanharam nem mesmo no momento da baixa, pois foi trazido pelo conselheiro tutelar).

Logo em seguida, pergunta se a juíza irá ajudá-lo, comentando que está internado porque não cumpriu uma medida sócio-educativa, e que "se eu bobear mais uma vez ela me disse que vai me mandar pra FASE”.

O jovem, segundo as informações do prontuário, foi internado, além da dependência química, por ter reincidido nas fugas de casa e por ter se envolvido com um grupo de infratores, tendo, inclusive, já assaltado a mão armada. Cabe dizer que ele já esteve internado no CIAPS/HPSP ainda quando criança, na ala infantil, devido ao envolvimento com drogas. Além disso, no entremeio das internações, Nelson chegou, temporariamente, a ser abrigado em uma instituição.

Como vemos, o percurso de Nelson evidencia uma recorrência pela internação psiquiátrica desde a infância. As instâncias promotoras de suas internações colocam como justificativa para a mesma uma preocupação com o futuro do jovem, questionando que tipo de adulto ele se tornará. Nesse sentido, pode-se dizer que boa parte das políticas públicas se preocupa não com a criança propriamente dita, mas com o seu futuro ${ }^{7}$. Procura-se, desse modo, tratar a criança e o jovem pensando no seu futuro adulto e, por vezes, esquece-se da sua questão mais urgente.

O que se depreende, porém, pelo resultado dessa "preocupação" das instituições é que elas acabam contribuindo para forjar o próprio futuro dos jovens, quando operam preconizando profecias auto-realizadoras pela via da individualização da culpa. No relato de Nelson isso se verifica no momento em que as instituições - especialmente o judiciário - colocam a internação como conseqüência de uma conduta " $b o b a "$ por parte do jovem.

Uma intervenção que procura incidir não na situação, mas no próprio sujeito - reproduzindo a lógica de produção de uma subjetividade individualizada-, encontra respaldo em um pressuposto desenvolvimentista que compreende o sujeito individualmente em cada etapa de seu desenvolvimento, evidenciando, com isto, uma lógica que dispõe de mecanismos de adaptação para que o indivíduo consiga se adequar a uma determinada configuração social. Isto é, a solução encontrada se aplica ao próprio sujeito - internando-o, por exemplo-, mas sem oferecer-lhe verdadeiramente a chance de sair desse itinerário.

Destacamos, novamente, que a ordem judicial se apresenta tanto como uma possibilidade de acesso para o jovem ao serviço de saúde mental quanto também como uma forma de punição. Assim, tal prática de encaminhamento tornouse corriqueira nos serviços de saúde mental, em especial, os que atendem os jovens usuários de drogas. Uma das justificativas relevantes apresentadas no documento judicial é a referência ao Estatuto da Criança e do Adolescente, argumentado no sentido de proteção ao público-alvo desta lei e como garantia de acesso ao direito à saúde.

Outro fator indicado pela trajetória de Nelson refere-se à situação de abandono, não apenas familiar, mas também de outras instituições. Nesse contexto, o que sobra para muitos jovens é a oportunidade de socialização que a droga oferece. $\mathrm{Ou}$, caso queiram sair dessa situação, ainda resta, como um percurso que exige um movimento solitário do jovem, "ter força de vontade" - como diz o próprio Nelson.

Ao que parece, a idéia de "instituição total" 8 pode ser pensada, através do que encontramos nos relatos dos jovens, como o próprio percurso que realizam, pois é deste itinerário, restrito e marginal, que os jovens não conseguem efetivamente sair.

Talvez o aspecto mais crucial que a trajetória desse jovem especificamente destaca é a implicação da internação com o enigma de "como agradar o juiz?”. Ou seja, Nelson não cumpriu uma determinada medida sócio-educativa e, como uma espécie de pena ou castigo, ele foi internado. Como o próprio jovem se interroga, o efeito dessa baixa no CIAPS parece ser o de tentar desvendar o que fazer para não ser mais encaminhado à internação. Contudo, Nelson, se não decifrar o desafio e "não se comportar bem", corre ainda o risco de ser encaminhado para a FASE. Dessa forma, as instituições são vistas e atuam eminentemente como punitivas.

Essa questão do enigma que se apresenta como internação psiquiátrica, especialmente 
pela via da ordem judicial, pode ser comparada à pergunta da Esfinge presente no mito de Édipo: "decifra-me ou te devoro". De certa forma, a pergunta se atualiza na situação dos jovens internados: como sair de um circuito sem ser devorado pelo mesmo? Como, enfim, sobreviver dentro desta lógica recorrente que captura sempre os mesmos? É o enigma imposto aos que não conseguem decifrar o caminho para uma “adaptação social". Cabe a Nelson, então, para que não reinterne outra vez, ou para evitar ser encaminhado à FASE, simular sua "adequação", já que não dispõe de equipamentos sociais que consigam ampliar seus laços.

E é dessa lógica, atualizada na ordem judicial, que se estabelece a realimentação do próprio circuito da internação psiquiátrica: providenciar meios para controlar a marginalidade, sob o título de proteger a ordem social. Pois, mesmo em tempos de exaltação ao Estatuto da Criança e do Adolescente, a própria lei é usada para promover punições aos jovens com o intuito de moralizálos em vez de oferecer-lhes alternativas. A dificuldade se impõe, a nosso ver, para todos, pois necessitam escapar de uma lógica individualista que subjetiva os jovens, os profissionais e os próprios serviços de saúde.

Para discutir essa parceria entre o poder judiciário e médico, relação que se expressa por meio do encaminhamento via ordem judicial, apresentamos a idéia de espelhos sociais de Santos 5 . Podemos pensar esse tipo de encaminhamento como uma espécie de estátua que paralisa outras articulações possíveis na vida dos jovens envolvidos, uma vez que produz uma recorrência que se dá para controlar e vigiar, e não para realizar uma interlocução positiva entre os jovens e as instituições da sociedade. É a estátua da Esfinge que controla, vigia, devora...

Ou seja, é dentro de uma organização hierárquica que se criam os fluxos nas relações interinstitucionais de modo que, dentro desta articulação, surgem núcleos que exercem poder sobrepujando outros saberes. E quem está cada vez mais afastado desse núcleo são aqueles a quem tais regulamentações se destinam: os jovens.

Dessa forma, forja-se uma produção de incapacidade, colocada em relações de poder, que sempre expressam trocas desiguais e hierárquicas. Santos afirma que, através de uma produção como essa é que se criam estratégias para despotencializar a força emancipatória de determinados grupos sociais. Nas palavras do autor 5 (p. 272): “Há (...) diferenças capacitantes e diferenças incapacitantes, tal como existem igualdades capacitantes e igualdades incapacitantes, e o critério para as distinguir tende a ser, na prática, extremamente contestado, senão opaco". Com isso, gera-se uma massificação da experiência - no caso, dessa juventude -, já que os próprios sujeitos aprendem a atribuir a si essa "incapacidade" que é socialmente produzida e forjada como pessoal.

No momento em que as experiências dos jovens são reconhecidas de modo pejorativo, sendo eles privilegiadamente vistos e tratados como delinqüentes, infratores e doentes se lhes estancam as possibilidades de saída. Cria-se a recorrência, a Esfinge os devora; "entre se quiser, saia se puder". É nessa configuração, forjada na relação dos percursos dos jovens com as redes jurídicas e sanitárias, que se materializa a recorrência da internação, subjetivando-os em todo este processo.

Dentro da questão dos percursos dos jovens à internação chama nossa atenção a completa ausência dos serviços substitutivos. Isto é, no caso dos jovens participantes da pesquisa, constatamos que nenhum deles, antes de chegar à internação, foi atendido por serviços substitutivos. Denominamos como serviços substitutivos aqueles que, conforme a definição do Ministério da Saúde 9 , atuam como alternativa à internação psiquiátrica, tais como os centros de atenção psicossocial.

Percebemos, nesse caso, o fenômeno de patologização de uma parcela social de jovens, reforçando a idéia de que a patologia é individual e sem relação com o contexto onde estes jovens estão inseridos. Assim, estabelece-se uma naturalização de processos sociais, do jovem pobre e delinqüente como representante de uma doença; e a "moléstia hereditária", em geral atribuída à pobreza, acaba sendo transformada em seu próprio destino.

Para encerrar a exposição das trajetórias apresentadas nas oficinas, vamos abordar o percurso de Ricardo. O jovem, de 15 anos, primeira internação no CIAPS, também morador da Grande Porto Alegre, diz que tinha vontade de viver na capital, onde costumava circular. No papel, faz o desenho do "casarão", local onde ia para usar drogas. Ricardo também já teve passagem pela FASE, sabendo, inclusive, em que artigo estava "enquadrado": "tava no 155, tia" (artigo do Código Penal que determina sanção à prática de furto). O jovem desenha a si e a um amigo, dizendo que "ele também precisava estar aqui se tratando; é que ele usa muita droga também”. Ricardo refere que pediu para ser internado, que tinha visto que perdeu o controle de si mesmo para a droga. Comenta que sua ex-namorada uma vez pediu a ele que escolhesse entre ela e a "pedra"; relembra que optou pelo vício e lamenta sua escolha justificando que gostava da menina, mas que o crack foi mais forte na sua decisão. Disse que não sabe se teria outra chance com a garota, mas fala que tem muita vontade de sair do CIAPS para se tratar 
realmente, pois quer mostrar para as pessoas que duvidam dele que é capaz de "sair dessa". Segundo o jovem, seus familiares acham que o vício é "sem-vergonhice".

Ricardo fala que da última vez que teve "fissu$r a$, os pais o amarraram com correntes ao pé da sua cama para que não saísse de casa. Relata que acabou quebrando a cama toda para poder ter os pés livres para caminhar; diz que saiu de casa com as correntes nos pés e foi, assim mesmo, fumar "pedra" (crack). Relata que foi o desespero de seus pais que o incentivou a buscar ajuda e a ver que podia morrer realmente: "Perdi o controle de mim pra virar escravo da droga”.

Destaca-se nessa trajetória o fato de haver um pedido por parte do próprio jovem para ser internado. Ricardo percebe a necessidade de ajuda e, em atitude de desespero, requer uma forma de contenção, crendo, por meio disto, conseguir fugir não apenas da droga, mas do itinerário que se impõe, ao revelar que somente a determinação, sem uma rede de apoio efetivo, não é eficaz.

Mais detidamente, o jovem expressa que o uso de drogas é entendido como um comportamento imoral por parte de sua família ("sem-vergonhi$c e$ ”). No entanto, esse tipo de entendimento não é exclusivo dos familiares, mas também de alguns serviços de saúde em que existe também uma interpretação moralizante do comportamento.

Outro fator que salta aos olhos no caso do jovem é a questão da lei. Ricardo conhece o artigo do Código Penal que pune a infração por ele cometida. Desse modo, torna-se importante analisar em que aspectos o Estatuto da Criança e do Adolescente consegue ser, efetivamente, uma ferramenta guardiã dos direitos dos jovens de maneira a não criminalizá-los pelos seus "erros", mas sim oportunizar uma outra alternativa capaz de lhes oferecer condições de participarem da sociedade sem ser pela via da estigmatização ou da reificação de atos infracionais.

De acordo com Fonseca 10, o Estatuto da Criança e do Adolescente é uma legislação que, se por um lado dispõe de direitos jamais obtidos em outros tempos para a infância e juventude brasileiras, por outro, dá margem a interpretações amplas que eufemizam vocábulos provocando uma grande distância entre a prática e a realidade.

Conforme Fonseca 10 (p. 106): "Parece que muitas pessoas acreditam na força mágica das palavras - como se o mero fato de falar da criança enquanto 'sujeito de direitos' pudesse trazer uma mudança revolucionária na vida dos jovens brasileiros". A autora, no entanto, não nega a importância dessa legislação, mas nos alerta de que somente o seu registro no papel não basta para assegurar uma conquista, enfatizando, assim, a necessidade da sociedade lutar pela concretização dos direitos que constam no Estatuto da Criança e do Adolescente enquanto lei.

Destacando o aspecto da marginalidade nos percursos dos jovens internados no CIAPS/HPSP, como acontece nos casos dos itinerários apresentados, percebemos que no contexto atual da internação psiquiátrica o que vemos parece um retorno à "História da Loucura" de Foucault 11.

Ou seja, a grande questão não é mais separar os pacientes psicóticos - os "loucos típicos" - dos demais grupos excluídos de participarem da sociedade, mas, como uma volta às primeiras páginas do livro desse consagrado autor, a promoção da internação para aqueles que são considerados marginais e, assim, inseri-los em categorias nosográficas capazes de patologizar e encobrir como doença mental determinados processos sociais que discriminam a pobreza e o desinvestimento da sociedade, produzindo uma espécie de não-existência 13 desses sujeitos.

Vivendo em um mundo onde o consumismo é a ditadura, a droga e o tráfico podem se tornar uma alternativa aos jovens que não encontram outras possibilidades sociais. Algumas investigações 12,13,14 indicam que o problema da violência, tráfico e juventude são muito mais complexos do que aquilo que pode ser entendido em uma perspectiva idiossincrática e restrita. Essas questões são um fenômeno de uma experiência típica da contemporaneidade na sociedade brasileira e do próprio sistema capitalista, em uma lógica ditatorial de um consumismo a qualquer custo. No que tange especificamente ao uso de drogas por uma parcela da juventude brasileira, Carlini-Marlatt 15 (p. 315) contribui ao dizer que "os jovens defasados nos estudos, com baixo desempenho na escola e com relacionamento familiar difícil, vivendo situações de violência doméstica e estudando no período noturno são os que apresentam maiores chances de consumir substâncias ilícitas (...). Nesses casos, o uso de drogas ilícitas parece ser menos resultado da oportunidade de usá-las do que da falta de oportunidade em outros domínios da vida social e afetiva".

De modo geral, podemos afirmar que todos os jovens participantes das oficinas estão em situação de marginalidade social: a marca de suas trajetórias se expressa pela ausência ou pela frágil ligação com instituições tidas como importantes pela sociedade, como a escola e a família, por exemplo. Soma-se a isso a questão do uso de drogas - em especial o crack - bem como a situação de pobreza econômica. Ou seja, é uma confluência de fatores que, quando associados, são potencializadores de um encaminhamento à internação psiquiátrica. 
Na mesma pesquisa, Carlini-Marlatt $15 \mathrm{diz}$ que, se por um lado a juventude pobre é suscetível ao uso de drogas - inclusive pela possibilidade de obter um "plano de carreira" pela via do tráfico - por outro, a juventude com maior poder econômico parece tender ao uso de drogas não com o intuito de substituir aquelas permitidas pela lei, mas para aumentar seu repertório de consumo.

Essa idéia também coincide com os trabalhos de Zaluar 16,17. Estes, por sua vez, apontam para uma crítica da situação da criminalidade associada à pobreza, explicada por muitos estudiosos praticamente como um fator único para justificar o crime pela pobreza. Entretanto, a autora fala de uma sinergia de fatores que cooperam com a situação do tráfico de drogas, por exemplo, como a concepção do consumo como valor da sociedade capitalista.

É no esforço de pensar um trabalho terapêutico que proponha não apenas inserções na comunidade onde moram jovens em situação de marginalidade social atendidos pelos serviços de saúde do Sistema Único de Saúde (SUS), mas um trabalho capaz de produzir reflexões que permitam a abertura de intervenções coletivas, que compartilhamos aqui a experiência desta pesquisa no CIAPS/HPSP. Pensamos que tal experiência possa ajudar a problematizar as diretrizes terapêuticas atreladas unicamente à lógica individualista, apontando para a complexa e restrita trama na qual esses jovens se inserem socialmente. Nesse aspecto, nenhuma instituição - hospitalar ou jurídica - é capaz de oferecer alternativas para que os jovens saiam desse "destino": somente uma articulação coletiva entre diversos atores sociais e instituições que acompanhem esses jovens poderão criar outras alternativas a esse circuito que explicita a clausura de seus próprios percursos.

\section{Aprisionados em um circuito: conclusões}

Retomando a pergunta deste trabalho: "como se produz, através do percurso dos jovens pelas chamadas redes sociais, a internação psiquiátrica no CIAPS/HPSP?", nos deparamos com uma resposta que mostra uma configuração, um desenho que retrata uma realidade complexa, às vezes cruel, destinada aos jovens em situação de marginalidade social.

Nesses casos, a internação psiquiátrica funciona tanto como resposta que dá legitimação de uma "individualidade fracassada" quanto reificação do lugar de marginalidade social desses jovens. O destino imposto é que somente em uma trajetória marginal eles poderão percorrer e experienciar suas vidas. Com isso, a interna- ção psiquiátrica - na grande maioria dos casos - perpetua a lógica capitalista da exclusão - ou melhor, de uma inclusão no "fora da sociedade" -, atualizada na atribuição do insucesso pessoal, como doença e/ou como condição existencial. E assim, os jovens são patologizados pela moratória social que lhes é imposta.

A ordem judicial, que por vezes garante o acesso a essa internação, funciona como uma via de acesso aos serviços de saúde, ao mesmo tempo em que também funciona como uma forma de punição a esses jovens marginalizados. No entanto, vislumbramos que um outro papel poderia ter o judiciário na vida desses jovens, justamente para lhes possibilitar um outro percurso, pela garantia, de fato, dos direitos dispostos no Estatuto da Criança e do Adolescente, dos quais os jovens deveriam usufruir.

Os serviços de saúde, por sua vez, também desempenham um papel paradoxal: servem tanto como uma via para ajudar os jovens a encontrar outras estratégias de vida, capazes de lhes mostrar outros caminhos, bem como para amarrá-los cada vez mais em um lugar estigmatizante, sem saída. Entretanto, o próprio serviço também está no jogo, muitas vezes, nas mãos de outras instâncias que interferem em suas ações, colocando-os em xeque-mate tal como acontece com os jovens internados.

Entrar nesse itinerário, nesse circuito aprisionante, não é uma questão do querer, da vontade - isso nos remeteria novamente a um pressuposto individualista. É a forma de interação social possível, em que o jovem tem poucas chances de criar novos lances, novas estratégias de jogadas, sendo levado a uma posição em que não encontra saída, pois o xeque-mate está previamente agendado... O desafio que se coloca é, então, em como inventar uma saída.

Será que não é justamente a questão do coletivo que a droga impõe à ordem social? Sua organização em grupos que agem coletivamente, como uma injunção à sociedade, proporciona a criação de laços de pertencimento e um reconhecimento social negado a esses jovens por outras instituições tradicionais, como a escola e a família. Essa mesma organização gerida pela droga questiona as formas de viver em uma sociedade individualista.

Percebemos, assim, que para esses jovens a "saída” não é possível pela via individual, mas pela coletividade. Só há possibilidade de que eles realizem alguma outra estratégia de jogada na medida em que outras instâncias se firmarem como investidoras desses jovens - principalmente no sentido afetivo e social.

Escrevemos este artigo com a pretensão de contribuir para a discussão da internação com- 
pulsória de jovens em instituições totais, apontando a relação que se estabelece entre os campos médicos e jurídicos no atendimento desse público juvenil. Nosso intuito é propor uma reflexão sobre os rumos que a Reforma Psiquiátri- ca vem tomando no Brasil, uma vez que concluímos com este trabalho que, em nome de uma oficialidade nos caminhos de "recuperação" colocada pelas instituições, se reforça o estigma e a situação de exclusão social fadada ao jovem.

\section{Resumo}

Este artigo analisa a internação psiquiátrica de jovens, tomando-a não a partir de uma perspectiva psicopatológica individual, mas de uma dimensão subjetivo-social com base nos percursos desses jovens até a internação. O estudo foi realizado no Centro Integrado de Atenção Psicossocial para crianças e adolescentes do Hospital Psiquiátrico São Pedro, na cidade de Porto Alegre, Rio Grande do Sul, Brasil, por meio de oficinas com os jovens que estavam em atendimento na internação deste serviço. Percebeu-se uma recorrência que marca o percurso desses jovens e expressa um determinado modo de funcionamento da rede de atenção até a internação, acarretando na produção de um certo perfil desses jovens: pobreza sócio-econômica, baixa escolaridade e uso de drogas. Outro aspecto importante é o papel da ordem judicial nos encaminhamentos à internação, que obedece tanto a uma lógica de punição aos jovens e aos serviços, como também, paradoxalmente, constitui-se numa estratégia de acesso aos serviços de saúde.

Adolescente Hospitalizado; Hospitais Psiquiátricos; Transtornos Mentais

\section{Colaboradores}

A. C. C. Scisleski realizou a pesquisa e participou da redação do artigo. C. Maraschin orientou a pesquisa e participou da redação do artigo. R. N. Silva participou da redação do artigo.

\section{Agradecimentos}

Coordenação de Aperfeiçoamento de Pessoal de Nível Superior (CAPES). 


\section{Referências}

1. Scisleski ACC. "Entre se quiser, saia se puder": o percurso dos jovens pelas redes sociais e a internação psiquiátrica [Dissertação de Mestrado]. Porto Alegre: Programa de Pós-graduação em Psicologia Social e Institucional, Universidade Federal do Rio Grande do Sul; 2006.

2. Organização Mundial da Saúde. Classificações de transtornos mentais e de comportamento da CID-10. Porto Alegre: Editora Artmed; 1999.

3. Bentes ALS. Tudo como Dantes no Quartel d'Abrantes: um estudo das internações psiquiátricas de crianças e adolescentes através do encaminhamento judicial [Dissertação de Mestrado]. Rio de Janeiro: Escola Nacional de Saúde Pública, Fundação Oswaldo Cruz; 1999.

4. Santos BS. Um discurso sobre as ciências. São Paulo: Cortez Editora; 2000.

5. Santos BS. A crítica da razão indolente: contra o desperdício da experiência. São Paulo: Cortez Editora; 2002.

6. Nardi HC. A propriedade social como suporte da existência: a crise do individualismo moderno e os modos de subjetivação contemporâneos. Psicol Soc 2003; 15:37-56.

7. Pilotti F, Rizzini I, organizadores. A arte de governar crianças: a história das políticas sociais, da legislação e da assistência à infância no Brasil. Rio de Janeiro: Editora Universitária Santa Úrsula; 1995.

8. Goffman E. Manicômios, prisões e conventos. São Paulo: Editora Perspectiva; 1987.
9. Ministério da Saúde. Portaria GM 251/2002. Estabelece diretrizes e normas para assistência em hospitais psiquiátricos. Diário Oficial da União 2002; 31 jan.

10. Fonseca CLW. Os direitos da criança - dialogando com o ECA. In: Alves CF, Fonseca CLW, Terto Jr. V, organizadores. Antropologia, diversidade e direitos humanos: diálogos interdisciplinares. Porto Alegre: Editora da UFRGS; 2004. p. 103-15.

11. Foucault M. História da loucura na idade clássica. São Paulo: Editora Perspectiva; 2000.

12. Santos BS. Conhecimento prudente para uma vida decente: "um discurso sobre as ciências" revisitado. São Paulo: Cortez Editora; 2004.

13. Njaine K, Minayo MCS. A violência na mídia como tema da área da saúde pública: revisão da literatura. Ciênc Saúde Coletiva 2002; 7:285-97.

14. Zaluar A. Integração perversa: pobreza e tráfico de drogas. Rio de Janeiro: Editora FGV; 2004

15. Carlinni-Marlat B. Jovens e drogas: saúde, política neoliberal e identidade jovem. In: Abramo HW, Branco PPM, organizadores. Retratos da juventude brasileira: análises de uma pesquisa nacional. São Paulo: Fundação Perseu Abramo; 2005. p. 303-21.

16. Zaluar A. Exclusão e políticas públicas: dilemas teóricos e alternativas políticas. Rev Bras Ciênc Soc 1997; 12:29-47.

17. Zaluar A. Violência extra e intramuros. Rev Bras Ciênc Soc 2001; 16:145-64.

Recebido em 06/Dez/2006

Versão final reapresentada em 04/Jul/2007

Aprovado em 13/Jul/2007 